\title{
Modified silicone stent for difficult-to-treat massive hemoptysis: a pilot study of 14 cases
}

\author{
Junli Zeng, Xuemei Wu, Meihua Zhang, Liancheng Lin, Mingyao Ke \\ Department of Respiratory Centre, The Second Affiliated Hospital of Xiamen Medical College, Xiamen 361000, China \\ Contributions: (I) Conception and design: M Ke, J Zeng; (II) Administrative support: M Ke; (III) Provision of study materials or patients: X Wu, J \\ Zeng; (IV) Collection and assembly of data: M Zhang, L Lin; (V) Data analysis and interpretation: J Zeng; (VI) Manuscript writing: All authors; (VII) \\ Final approval of manuscript: All authors. \\ Correspondence to: Mingyao Ke. Respiratory Centre, The Second Affiliated Hospital of Xiamen Medical College, 566 Shengguang Road, Xiamen \\ 361000, China. Email: 13860166866@163.com.
}

\begin{abstract}
Background: Massive hemoptysis is a life-threatening event with limited therapeutic options. Bronchoscopic placement of stents may offer an alternative option for massive hemoptysis. However, traditional silicone stents have not been customized, making it difficult to tailor to individual patient's needs for achieving optimal hemostasis. To investigate the efficacy and safety of the modified silicone stent in patients with difficult-to-treat massive hemoptysis.

Method: Between May 2016 and November 2018, we enrolled 14 patients who underwent bronchoscopic placement of the modified silicone stent, which was fabricated manually based on the Y-shaped silicone stent by tailoring and suturing on site. We recorded the technical success, clinical success, and complications. Patients were followed up for recording the recurrence of massive hemoptysis and complications.

Results: Placement of the modified silicone stent was successful in all 14 patients with a mean duration of 69.6 minutes (technical success rate: 100\%). After stenting, no further massive hemorrhage episodes recurred in 12 patients (clinical success rate: 85.7\%). Two cases suffered from recurrent hemoptysis in 4 and 6 days after stenting, respectively. The main complications were sputum plugging, granuloma proliferation and pulmonary infection such as pneumonia. There were no adverse events of stent migration and suture dehiscence. After a median follow-up of 5.8 (range, 0.3-21.3) months, three patients withdrew and seven patients succumbed. Only one patient died of uncontrolled pneumonia which was possibly related to stent placement.

Conclusions: The modified silicone stent is an effective and safe gate-keeping therapeutic option for difficult-to-treat massive hemoptysis.
\end{abstract}

Keywords: Modified silicone stent; massive hemoptysis; rigid bronchoscopy

Submitted Jun 27, 2019. Accepted for publication Dec 03, 2019.

doi: $10.21037 /$ jtd.2019.12.47

View this article at: http://dx.doi.org/10.21037/jtd.2019.12.47

\section{Introduction}

Hemoptysis is a common respiratory symptom, accounting for $6.8 \%$ of pulmonary outpatient visits, and $11 \%$ of admissions to pulmonary wards (1). Hemoptysis ranges from mild (i.e., blood-streaks) to severe (i.e., hemorrhagic shock). It has been estimated that $4.8-14.0 \%$ of patients presenting with hemoptysis would finally develop massive hemoptysis (1-5). Massive hemoptysis [expectoration of a large volume of blood or rapid loss of blood (from 100 to $>1,000 \mathrm{~mL}$ per day)] (5-7) is a life-threatening symptom, with the mortality ranging from $6.5 \%$ to $38.0 \%(8-11)$.

Prompt and effective management is crucial to major hemoptysis. Currently, mainstream treatment options include medication, bronchoscopic intervention, vascular embolization and surgical resection $(12,13)$. While medication (i.e., tranexamic acid, coagulase) may be effective for mild-to-moderate hemoptysis, vascular 
embolization and surgical resection are usually reserved for major or recalcitrant hemoptysis $(6,7)$. The highest reported immediate success rate of bronchial artery embolism (BAE) could reach to $100 \%$, but the high recurrence could have influenced the long-term outcomes, especially in malignant lung diseases (14-17). Surgery has the limitations for massive hemoptysis because the efficacy is short-lived and the post-operative mortality remains considerable $(18,19)$. Currently, surgery is mainly reserved for cases of early or repeated recurrence of hemoptysis despite BAE (20). Moreover, there are some clinical conditions (i.e., poor functional status, moderate-to-severe lung function impairment, bilateral pulmonary disease) that commonly constitute the contraindications for surgery $(5,6)$.

Bronchoscopic intervention (especially rigid bronchoscopy) which has the merits of the ease of clearing the blood while maintaining adequate ventilation and clear vision, has been widely applied for the management of massive hemoptysis $(12,13,21)$. Bronchoscopic interventions for hemostasis include intubation of endotracheal tube with a greater diameter, balloon tamponade, endobronchial stent, silicone spigot, laser photocoagulation and argon plasma coagulation, most of them have been applied for mildto-moderate hemoptysis only. Successful placement of endobronchial stents, which helped achieve hemostasis for difficult-to-treat massive hemoptysis, has been documented in some case reports $(22,23)$. In these studies, stent placement was usually reserved as the salvage therapy for difficult-to-treat massive hemoptysis by both blockade and separation of the bleeding source, thereby maintaining the patency of central airways.

The silicone stents have been increasingly adopted to manage benign tracheal and tracheobronchial stenosis $(24,25)$ and airway fistula (26-28). In this study, we evaluated the efficacy and safety of the modified silicone stents in patients with major hemoptysis. Our findings indicated the roles of the modified silicone stents as the gate-keeping therapeutic approach for massive hemoptysis that failed to respond to alternative existing approaches.

\section{Methods}

\section{Patients}

In this single center study, we enrolled patients with massive hemoptysis in the bronchoscopy center between May 2016 and November 2018. The inclusion criteria were: (I) the volume of blood expectoration being $500 \mathrm{~mL}$ or greater in 24 hours, or greater than $100 \mathrm{~mL}$ within 1 hour, or hemoptysis leading to airway obstruction and hemodynamic instability $(6,7)$; (II) patients who were unsuitable or unwilling to receive intravascular interventional therapy or surgery; (III) hemoptysis recurred repeatedly after surgery and/or intravascular interventional therapy; Exclusion criteria (29) consisted of: (I) severe cardiovascular and cerebrovascular diseases; (II) severe thrombocytopenia and/or severe coagulopathy; (III) severe facial injuries that hampered rigid bronchoscope placement; (IV) cervical spine instability; (V) bilateral diffuse hemorrhage. Patients were further categorized into unstable group (developed airway obstruction with ongoing bleeding) and the temporarily stable group (had a high risk of airway obstruction).

The protocol has been approved by the Institutional Review Board of The Second Affiliated Hospital of Xiamen Medical College (Approval No: 2018033) and all patients signed written informed consent before rigid bronchoscopy.

\section{Clinical data review}

We extracted the following clinical information from medical records, including age, gender, primary underlying disease, previous treatment, the duration of massive hemoptysis, the site of the occluded segment, recurrence of massive hemoptysis, complications and the duration of follow-up. The duration of massive hemoptysis was calculated as the time from the onset of massive hemoptysis until stent placement. We analyzed the technical success rate and clinical success rate. Technical success was defined as the successful fabrication and placement of the modified silicone stent that led to immediate hemostasis during bronchoscopy. Clinical success was defined as no ongoing massive hemorrhage during follow-up. We recorded, if any, the complications such as airway rupture, stent migration, suture dehiscence, granuloma proliferation, sputum plugging and respiratory tract infection.

\section{Bronchoscopic procedures}

The emergency endoscopic management was required in unstable group, while placement of the stent was usually achieved between the intervals of two neighboring episodes of hemoptysis in stable group. The bronchoscopic procedures were as follows:

Immediately following general anesthesia, rigid bronchoscopy was inserted with close monitoring of electrocardiogram and continuous ventilation. We took 

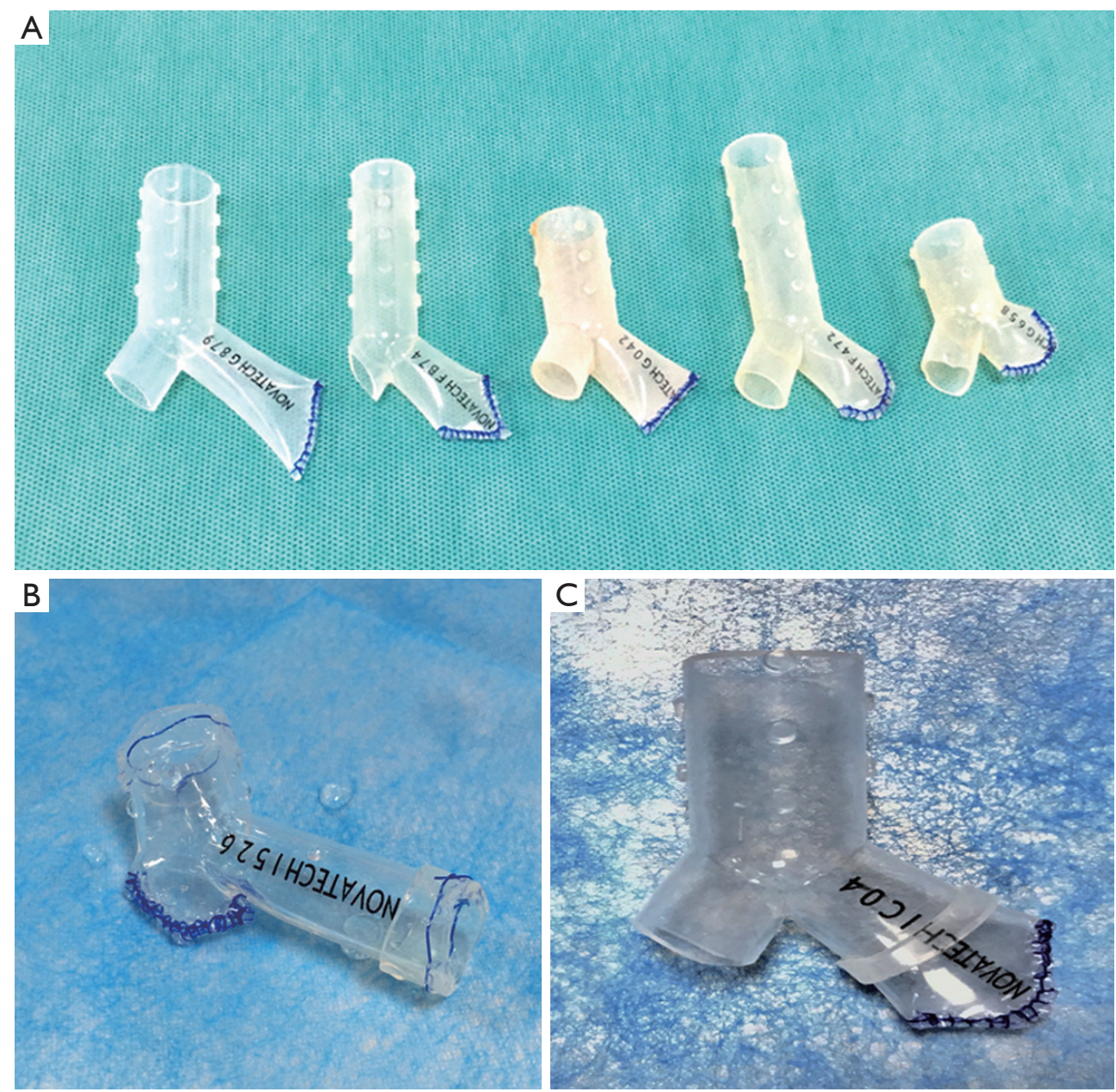

Figure 1 Illustration of the modified silicone stent. (A) The modified silicone stent consisted of the main branch, the lateral branch, the occluded branch; (B) the suitable stent rings were sutured to the main branch and the lateral branch of Silicone stent; (C) the stent ring was sutured to the occluded branch.

precaution of active bleeding during operation, including local instillation of hemostatic medications, balloon tamponade, intubation supplies with endotracheal tubes with larger sizes. In unstable group, these measures were initially performed to maintain airway stabilization before stent placement. The flexible bronchoscopy was performed before stent placement to identify the site of bleeding. Furthermore, the length and the inner diameter of airway lesion were measured for selection of the appropriate stent when becoming stable. To further confirm the luminal diameter of the target bronchus, the sterilized straight stent segments with different outer diameters were used under rigid bronchoscopy to detect the optimal size of the stent.

Commercial customization of the silicone stent would be impractical, hence, we have manually modified the stent's size during bronchoscopy. After confirming the size, one of the branches of the Y-shaped stent was randomly selected as the occluded branch. Based on flexible bronchoscopic findings, the length of each branch was manually adjusted with scissors. The distal end of the occluded branch was sealed with nylon wires by continuous locking suture, in which the distance between the continuous sutures should be less than $2 \mathrm{~mm}$ (5-10 $\mathrm{mm}$ in common surgeries) to avoid leakage.

Finally, the modified silicone stent consisted of the occluded branch, the main branch and the lateral branch (Figure 1A). To ensure that the occluded branch has tightly adhered to the bronchial wall, the outer diameter of the occluded branch should be approximately $10 \%$ greater than that of the affected bronchus. We fitted a suitable stent ring by nesting or suturing to the selected stent in case the size 


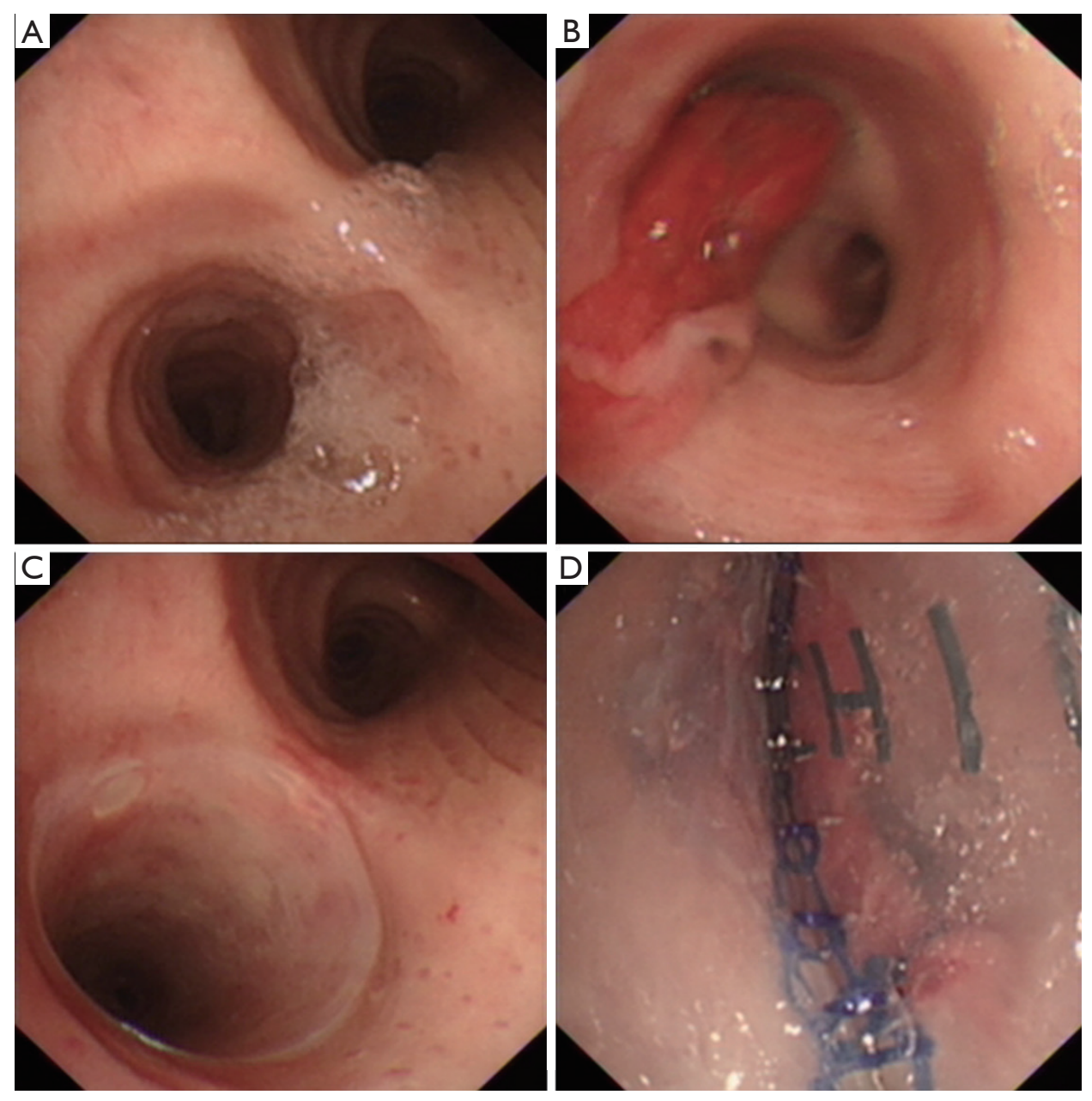

Figure 2 The bronchoscopic view of the stent placement. Stent placement in an 85 -year-old male patient with bronchiectasis. (A) Bronchoscopic image of the carina, left main bronchus and right main bronchus; (B) the blood clot in the opening site of left superior bronchus before stenting; (C) the left main bronchus after stenting; (D) the inner surface of the occluded branch in left superior bronchus.

was unfit (either for the outer diameter or the length of occluded branch). Efforts have been made to ensure that the stent would fit tightly to the bronchial wall (Figure 1B,C).

Thereafter, the modified stent was placed into the folding system. Under general anesthesia, the stent was implanted into the appropriate location through rigid bronchoscopy (Figure 2), and adjusted by using the surgical grasping forceps or foreign-body forceps. All patients were carefully and continuously monitored. After stenting, the expectorants were used through nebulization, intravenous injection and oral administration. Within one week after stenting, all patients underwent bronchoscopy and chest CT to identify the location of stent and airway patency.

\section{Follow-up schemes}

We followed-up patients after the first bronchoscopy. The frequency of follow-up depended upon the overall wellbeing and complications. Overall, patients were evaluated bronchoscopically for three times weekly or once monthly. Patients were invited to undergo computed tomographic scans once monthly or bimonthly. The reassessment included respiratory symptoms (cough, sputum, and dyspnea), recurrence of massive hemoptysis and the stentrelated complications. We recorded the interval from stent placement in patients who experienced recurrence of massive hemoptysis. 
Table 1 Clinical characteristics of patients

\begin{tabular}{|c|c|c|c|c|c|c|c|c|}
\hline No & $\begin{array}{l}\text { Age } \\
\text { (yrs) }\end{array}$ & Sex & Primary disease & Prior treatment & $\begin{array}{l}\text { Occluded } \\
\text { bronchi }\end{array}$ & $\begin{array}{c}\text { Type of stent } \\
(\text { Ya-b-b })^{\S}\end{array}$ & $\begin{array}{l}\text { Duration of } \\
\text { procedure }\end{array}$ & $\begin{array}{l}\text { Follow-up } \\
\text { (months) }\end{array}$ \\
\hline 1 & 60 & Male & Lung cancer & None & LMB & Y15-12-12 & 65 & 0.3 \\
\hline 3 & 38 & Male & $\begin{array}{l}\text { Post-tuberculous } \\
\text { destroyed lung }\end{array}$ & BAE and surgery & LMB & $Y 16-13-13$ & 74 & 21.3 \\
\hline 5 & 57 & Male & Lung cancer & None & RSB & Y16-13-13 & 60 & 5.2 \\
\hline 6 & 66 & Male & Lung cancer & None & RMB & Y18-14-14 & 68 & 6.4 \\
\hline 7 & 85 & Male & Bronchiectasis & None & LSB & Y15-12-12 & 59 & 1.3 \\
\hline 8 & 62 & Male & Lung cancer & None & RIB & $Y 16-13-13$ & 78 & 3.2 \\
\hline 11 & 77 & Male & $\begin{array}{l}\text { Destroyed lung after } \\
\text { purulent pleurisy }\end{array}$ & None & RMB & Y15-12-12 & 66 & 12.8 \\
\hline 12 & 67 & Male & $\begin{array}{l}\text { Post-tuberculous } \\
\text { destroyed lung }\end{array}$ & BAE & $\mathrm{RMB}$ & $Y 16-13-13$ & 58 & $1.2^{*}$ \\
\hline 13 & 50 & Male & Lung cancer & None & LMB & Y15-12-12 & 73 & 6.8 \\
\hline 14 & 48 & Male & Lung cancer & None & RMB & Y15-12-12 & 96 & $2.8^{*}$ \\
\hline
\end{tabular}

RMB, right main bronchus; LMB, left main bronchus; LSB, left superior lobar bronchus; RSB, right superior lobar bronchus; RIB, right inferior lobar bronchus. *the patient who was lost to follow-up before the deadline. " "Y" refers to the shape of stent, "a" and "b" refer to the outer diameters of the main branch and the two branches, respectively. The diameter is presented as millimeters.

\section{Statistical analysis}

SPSS version 18.0 (SPSS Inc., USA) was used for data analysis. Continuous characteristics were expressed as mean \pm standard deviations, and categorical variables were presented as count (percentage).

\section{Results}

We enrolled 14 patients who underwent bronchoscopic placement of the modified Silicone stent. Table 1 demonstrates the patient's characteristics and previous management for massive hemorrhage. All patients were males, with the mean age of 58.5 (range, 38-85) years. Ten patients had metastatic lung cancer, three had destroyed lung due to previous pulmonary infections (two had tuberculosis and one had purulent pleurisy), and one had bronchiectasis. All patients had responded poorly to vasoconstrictive agents. The median duration of massive hemoptysis was 35.5 (range: 11.8-104.3) hours. One patient had undergone both BAE and surgery, which failed to ameliorate massive hemoptysis. Two patients underwent BAE before stenting which still failed to achieve hemostasis. The other 11 cases were unsuitable (i.e., high risks of central airway blockage, non-active arterial bleeding,_poor global conditions) or unwilling to undergo intravascular interventions or surgery. Based on our grouping scheme, four patients were categorized in unstable group and ten in temporarily stable group.

The modified silicone stents were successfully inserted to the target bronchus in 14 patients. Notably, immediate control of massive hemorrhage was unanimously achieved during bronchoscopy (technical success rate: $100 \%)$. Dyspnea was ameliorated in eight patients $(57.1 \%)$ immediately after stent placement. The mean duration from bronchoscopic inspection to successful placement of the stent was 69.6 (range, 58.0-96.0) minutes. The mean duration of stent fabrication was 30.2 (range, 21.0-36.0) minutes. Each patient received the placement of only one stent. Three sizes of silicone stents were used, including $\mathrm{Y}$ 

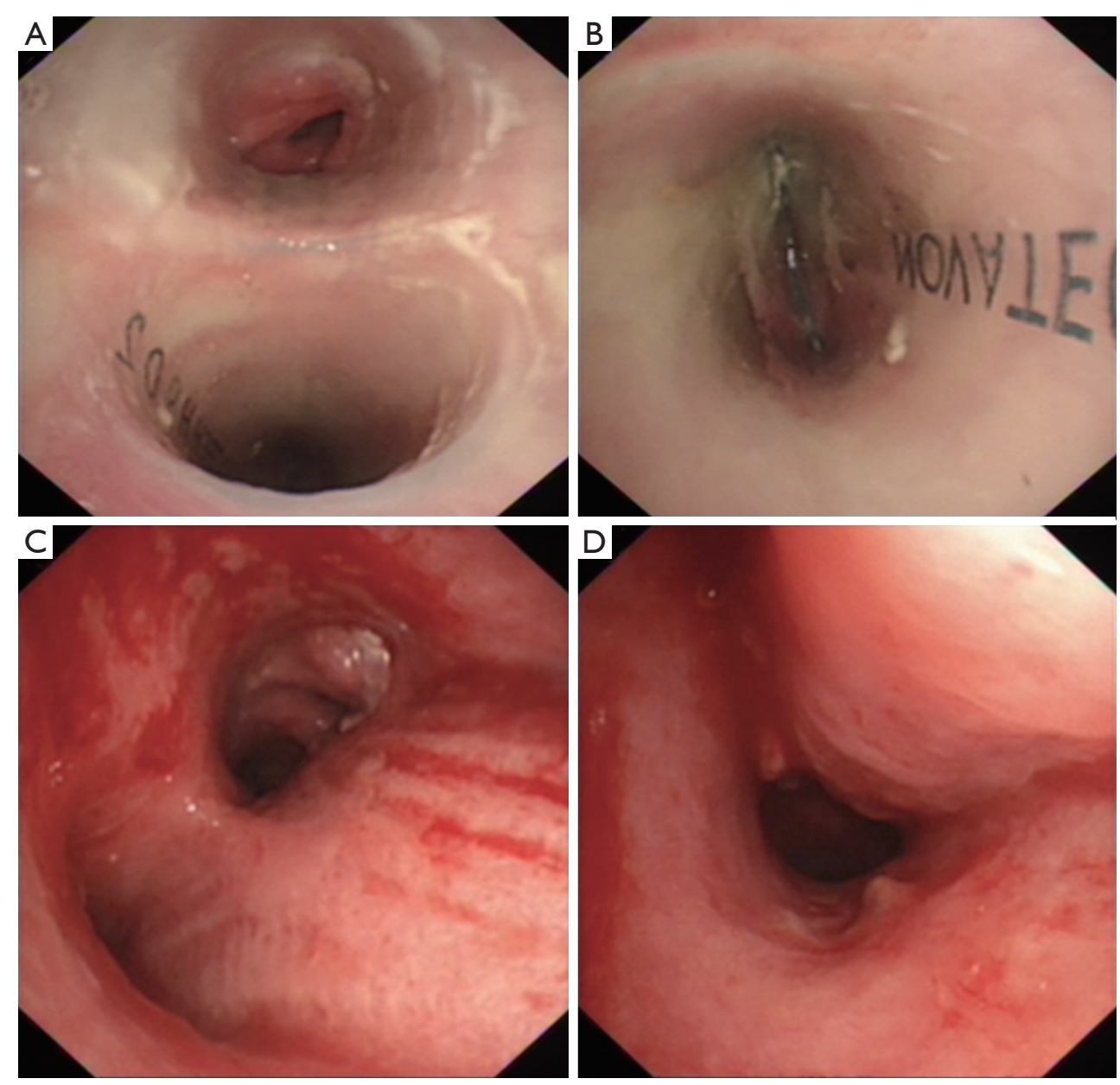

Figure 3 Removal of the modified silicone stent. The courses of removal of the modified silicone stent in a 38-year-old patient with posttuberculous destroyed lung. (A) The branches of the Y stent stretched into left main bronchus and right main bronchus, respectively; (B) the occluded branch of the stent in the left main bronchus; (C) bronchoscopic view of the carina, left main bronchus and right main bronchus after stent removal; (D) bronchoscopic view of left main bronchus after stent removal.

15-12-12 in six cases, Y 16-13-13 in six cases and Y 18-14-14 in two cases ( $\mathrm{Y}$ denotes the shape of stent; the numbers denoted the outer diameter of the main branch and the two branches, respectively). The occluded branches were deployed on the right main bronchus in four cases, the left main bronchus in five cases, the right superior lobar bronchus in two cases, the left superior lobar bronchus in two cases and the right inferior lobar bronchus in one case.

To better achieve sealing, the rings of stent were connected to the $\mathrm{Y}$ stent by sleeve-suture for full dilation of the outer diameter in three cases. The stent ring was connected to the occluded branch in two cases, and the main branch and the lateral branch in one each case, respectively.

The median follow-up was 5.8 (range, 0.3-21.3) months.
Four patients underwent tracheal intubation to maintain ventilation after stenting and successfully extubated within 6 days (mean: 3.3 days). Twelve cases experienced no recurrence of massive hemorrhage after only a single course of intervention (clinical success rate: $85.7 \%$ ), except for several episodes of sputum production with blood streaks in 4 cases. Stents were removed safely at 5.7 and 21.1 months in two patients (who had bronchiectasis and post-tuberculous destroyed lungs), respectively. Dynamic observations of stent placement to removal are demonstrated in Figure 3. Two cases (14.3\%) suffered from recurrence of massive hemoptysis after the first stent placement, which occurred at day 4 and 6 , respectively. The recurrence of massive hemoptysis was resolved by 
the replacement of a second stent. However, one of the two recurrent cases succumbed 11 days after the second procedure due to severe aspiration pneumonia.

Stent placement was well tolerated in all patients. Cough and postoperative retrosternal pain were the two most common adverse events, most of which could be spontaneously relieved within 2 weeks. Antitussive agents (i.e., dextromethorphan and codeine) and a three-step analgesic scheme (i.e., diclofenac, celecoxib, tramadol, morphine and adanon) were applied to relieve the intractable symptoms. No stent migration, airway rupture and suture dehiscence took place during follow-up. Pulmonary infection occurred in five patients $(35.7 \%)$ within a week after stenting, four of whom with mild infection were managed by intravenous antibiotics while one cases mentioned above suffered uncontrolled diffuse pneumonia. Granuloma proliferation was identified in all cases within a month after stenting. However, severe granuloma proliferation was detected in a single case only (7.1\%), which was managed by cryosurgery and argon plasma coagulation. Mucus plugging was also common after stenting (seen in nine cases, $64.3 \%$ ), which could be managed via bronchoscopy at different frequency (from twice weekly to once monthly). In addition, three cases were lost to follow-up and seven patients succumbed. The causes of death were primary tumor progression $(\mathrm{n}=3,21.4 \%)$, left heart failure $(n=2,14.3 \%)$, respiratory failure $(n=1,7.1 \%)$ and uncontrolled pneumonia ( $\mathrm{n}=1,7.1 \%$, which was possibly related to stent placement).

\section{Discussion}

Our study suggested that placement of the modified silicone stent under rigid bronchoscopy could effectively and safely manage the massive hemoptysis that responded poorly to alternative therapeutic approaches. This is the first study with the largest sample size which explores the efficacy and safety of the modified silicone stent for difficult-to-treat massive hemoptysis.

The common causes of massive hemoptysis included advanced lung cancer, tuberculosis, bronchiectasis and necrotizing pneumonia $(6,30)$. Unfortunately, no expert consensus exists on defining massive hemoptysis, especially difficult-to-treat massive hemoptysis. Currently, a preferred definition is based on the presence of severe adverse events such as respiratory failure and hemodynamic instability (30) which has often been recognized as a potentially lethal condition with limited therapeutic options. Maintaining airway patency and fluid resuscitation have been crucial $(1,31)$.
Fiberoptic bronchoscopy should be immediately performed to clear airway secretions and blood clots, which would provide the crucial time window for further rescue management.

Conventional medication (i.e., topical instillation of vasoconstrictive agents) is effective in patients with mildto-moderate, but not massive, hemoptysis $(32,33)$. BAE remains the first-line treatment for massive hemoptysis because it is less invasive and can achieve satisfactory short-term outcome in most cases (34-36). The immediate success rate of BAE reportedly ranged from $60 \%$ to $100 \%$ (12-14,34). However, BAE is not well tolerated among patients with malignancy (37), and can only be performed when patients remain hemodynamically stable and have adequate oxygen saturation. Moreover, the efficacy and recurrence depend largely on the underlying etiology (i.e., higher treatment success rate for benign $v s$. malignant diseases). Furthermore, recurrence of massive hemoptysis was common among patients with advanced lung cancer $(38,39)$ who were often unable to receive repeated courses of BAE. For instance, Syha et al. (40) reported that the recurrence-free survival in patients with malignancy was $34 \%$ at year 1 and $0 \%$ at year 3, which was significantly lower than that in benign diseases $(94 \%$ at year 1 and $87 \%$ at year 10$)$. Notably, BAE would not be recommended for non-active arterial bleeding, or a lack of contrast enhancement of the mass on chest computed tomographic scans (34). Surgery is an alternative option for massive hemoptysis, but the postoperative mortality could range from $20 \%$ to $30 \%(12,41)$ and the postoperative recurrence was reportedly high. Importantly, surgical resection cannot be tolerated in patients with poor functional status (i.e., moderateto-severe lung function impairment). Therefore, surgery has limitations for the management of massive hemoptysis.

There are other bronchoscopic interventions that help achieve hemostasis (6). Local instillation of topical vasoconstrictive agents is effective in mild-to-moderate, but not massive, hemoptysis. Laser photocoagulation, argon plasma coagulation and electrocautery can only be used in bronchoscopically visible central airway lesions, which only account for a small proportion of cases with massive hemoptysis. Although successful placement of silicone spigot has been described in some studies (42-44), no follow-up investigations have been conducted. It was used as temporary treatment and was removed in a short time. Unlike balloon tamponade, the effect of endobronchial obstruction is limited to a bronchial subsegment. Furthermore, endobronchial placement of the spigot is challenging particularly for emergency use. 
While bronchoscopic intervention by intubation with an endotracheal tube or placement of endobronchial balloons could offer a temporary relief, endobronchial stent placement offers a more durable protection of the unaffected lung without prolonging mechanical ventilation. Stent placement had been occasionally reported to effectively manage massive hemoptysis in some case report (especially in those who failed to respond to alternative treatments) $(22,23,45-47)$. The stent used to seal the airway mainly included the covered metallic and silicone stent. Although the former could be deployed more readily, it was impractical to be fabricated manually to fit the airway morphology well. In fact, placement of the modified silicone stent has become the preferred approach for clinical application (48). The feasibility of manual fabrication has tailored to the various shapes and sizes of airways. Moreover, the stent can be readily withdrawn from the airways. The smooth inner surface may facilitate the clearance of airway secretions. Furthermore, the studs have been designed to prevent the stent from migration.

There are more reasons that justify stent placement in our scenario. Endobronchial tamponade has been the palliative therapeutic approach, which provides the crucial time window for subsequent treatment. However, the patients in poor general conditions (especially those with advanced malignant diseases) cannot tolerate the major complications in the subsequent treatments. Building on our experience for managing malignant airway stenosis and fistula, we have explored for the relatively long-term efficacy of the modified silicone stent. The successful placement of the stent can avoid additional interventions, which could also be cost-effective. Hence, placement of the modified silicone stent could be deemed as the gate-keeping approach for difficult-to-treat massive hemoptysis, especially in patients with unstable airway conditions, poor response to mainstream treatments and a limited life expectancy. Moreover, there are very few absolute contraindications (described in the exclusion criteria), rendering it potentially suitable for use in a variety of clinical conditions. However, there remain some disadvantages for the modified silicone stent. First, the stent may induce irritating cough because it is a foreign body. Second, displacement could be potentially life-threatening. Third, rigid bronchoscopy may not be available universally given the need for specialized equipment and training (13).

The proper precaution in peri-operative period is a significant factor to the clinical success of stent placement. We have provided circulatory and ventilatory supports by establishing the intravenous channel and continuous ventilation. The bronchoscopic instruments were ready for emergency use. The general anesthesia can avoid the coughinduced hemoptysis. Besides, the appropriate prevention and management of complications have substantially improved the efficacy and patient's tolerance. The stent has been tailored to the size of the airway walls, thus forming tight seals which could strengthen the blocking effect and reduce the risk of displacement. The standardized techniques of suture might have further avoided suture dehiscence. The use of expectorant through nebulization, intravenous injection and oral administration has a role in alleviating airway mucus plugging. The application of prophylactic and therapeutic antibiotics in the perioperative period could further reduce the risk of complications especially chest infections. Finally, bronchoscopic reassessment also helped maintain the airway patency.

There is no consensus on the optimal duration of stent placement. For patients with benign disease, the stent could be removed safely when the culprit lesion had been removed. However, the optimal timing to remove the stent remains controversial $(49,50)$. For malignant diseases, however, stent removal is not recommended (49-51).

There are notable limitations of our study. This was a retrospective analysis, making it difficult to perform survival analysis given the incomplete data recording. We did not compare the efficacy with other existing treatment approaches. However, massive hemoptysis is known to respond poorly to other candidate treatment approaches in all cases. Moreover, we did not compare our data with the historical documentation because the study design and endpoints were not directly comparable.

\section{Conclusions}

In conclusion, the modified Silicone stent is effective and safe for difficult-to-treat massive hemoptysis, especially in malignant diseases. Further prospective studies with large sample sizes are warranted.

\section{Acknowledgments}

We sincerely thank Prof. Wei-jie Guan (State Key Laboratory of Respiratory Disease, Guangzhou Institute of Respiratory Health, The First Affiliated Hospital of Guangzhou Medical University) for his help with the manuscript.

Funding: None. 


\section{Footnote}

Conflicts of Interest: The authors have no conflicts of interest to declare.

Ethical Statement: The authors are accountable for all aspects of the work in ensuring that questions related to the accuracy or integrity of any part of the work are appropriately investigated and resolved. The protocol has been approved by the Institutional Review Board of The Second Affiliated Hospital of Xiamen Medical College (Approval No: 2018033) and all patients signed written informed consent before rigid bronchoscopy.

Open Access Statement: This is an Open Access article distributed in accordance with the Creative Commons Attribution-NonCommercial-NoDerivs 4.0 International License (CC BY-NC-ND 4.0), which permits the noncommercial replication and distribution of the article with the strict proviso that no changes or edits are made and the original work is properly cited (including links to both the formal publication through the relevant DOI and the license). See: https://creativecommons.org/licenses/by-nc-nd/4.0/.

\section{References}

1. Dweik RA, Stoller JK. Role of bronchoscopy in massive hemoptysis. Clin Chest Med 1999;20:89-105.

2. Corey R, Hla KM. Major and massive hemoptysis: reassessment of conservative management. Am J Med Sci 1987;294:301-9.

3. Johnston H, Reisz G. Changing spectrum of hemoptysis. Underlying causes in 148 patients undergoing diagnostic flexible fiberoptic bronchoscopy. Arch Intern Med 1989;149:1666-8.

4. Valipour A, Kreuzer A, Koller H, et al. Bronchoscopyguided topical hemostatic tamponade therapy for the management of life-threatening hemoptysis. Chest 2005;127:2113-8.

5. Radchenko C, Alraiyes AH, Shojaee S. A systematic approach to the management of massive hemoptysis. J Thorac Dis 2017;9:S1069-86.

6. Sakr L, Dutau H. Massive hemoptysis: an update on the role of bronchoscopy in diagnosis and management. Respiration 2010;80:38-58.

7. Rali P, Gandhi V, Tariq C. Massive Hemoptysis. Crit Care Nurs Q 2016;39:139-47.

8. Hirshberg B, Biran I, Glazer M, et al. Hemoptysis: etiology, evaluation, and outcome in a tertiary referral hospital. Chest 1997;112:440-4.

9. Shin B, Koh WJ, Shin SW, et al. Outcomes of Bronchial Artery Embolization for Life-Threatening Hemoptysis in Patients with Chronic Pulmonary Aspergillosis. PLoS One 2016;11:e0168373.

10. Ong TH, Eng P. Massive hemoptysis requiring intensive care. Intensive Care Med 2003;29:317-20.

11. Fartoukh M, Khoshnood B, Parrot A, et al. Early prediction of in-hospital mortality of patients with hemoptysis: an approach to defining severe hemoptysis. Respiration 2012;83:106-14.

12. Ittrich $H$, Bockhorn $M, K$ lose $H$, et al. The Diagnosis and Treatment of Hemoptysis. Dtsch Arztebl Int 2017;114:371-81.

13. Davidson K, Shojaee S. Managing Massive Hemoptysis. Chest 2020;157:77-88.

14. Panda A, Bhalla AS, Goyal A. Bronchial artery embolization in hemoptysis: a systematic review. Diagn Interv Radiol 2017;23:307-17.

15. Swanson KL, Johnson CM, Prakash UB, et al. Bronchial artery embolization: experience with 54 patients. Chest 2002;121:789-95.

16. Fruchter O, Schneer S, Rusanov V, et al. Bronchial artery embolization for massive hemoptysis: long-term followup. Asian Cardiovasc Thorac Ann 2015;23:55-60.

17. Chen J, Chen LA, Liang ZX, et al. Immediate and long-term results of bronchial artery embolization for hemoptysis due to benign versus malignant pulmonary diseases. Am J Med Sci 2014;348:204-9.

18. Shigemura N, Wan IY, Yu SC, et al. Multidisciplinary management of life-threatening massive hemoptysis: a 10year experience. Ann Thorac Surg 2009;87:849-53.

19. Jougon J, Ballester M, Delcambre F, et al. Massive hemoptysis: what place for medical and surgical treatment. Eur J Cardiothorac Surg 2002;22:345-51.

20. Fartoukh M, Khalil A, Louis L, et al. An integrated approach to diagnosis and management of severe haemoptysis in patients admitted to the intensive care unit: a case series from a referral centre. Respir Res 2007;8:11.

21. Diaz-Mendoza J, Peralta AR, Debiane L. Rigid Bronchoscopy. Semin Respir Crit Care Med 2018;39:674-84.

22. Dalar L, Ozdemir C, Sokucu S, et al. The management of near-fatal hemoptysis with left secondary carinal y stent. Case Rep Pulmonol 2014;2014:709369.

23. Barisione E, Genova C, Grosso M, et al. Palliative treatment of life-threatening hemoptysis with silicone stent insertion in advanced lung cancer. Monaldi Arch Chest Dis 2017;87:781. 
24. Dutau H. Airway stenting for benign tracheal stenosis: what is really behind the choice of the stent? Eur J Cardiothorac Surg 2011;40:924-5.

25. Dumon JF. A dedicated tracheobronchial stent. Chest 1990;97:328-32.

26. Tayama K, Eriguchi N, Futamata Y, et al. Modified Dumon stent for the treatment of a bronchopleural fistula after pneumonectomy. Ann Thorac Surg 2003;75:290-2.

27. Lawler LP, Fishman EK. Multi-detector row CT of thoracic disease with emphasis on 3D volume rendering and CT angiography. Radiographics 2001;21:1257-73.

28. Ferraroli GM, Testori A, Cioffi U, et al. Healing of bronchopleural fistula using a modified Dumon stent: a case report. J Cardiothorac Surg 2006;1:16.

29. Batra H, Yarmus L. Indications and complications of rigid bronchoscopy. Expert Rev Respir Med 2018;12:509-20.

30. Kvale PA, Selecky PA, Prakash UB. Palliative care in lung cancer: ACCP evidence-based clinical practice guidelines (2nd edition). Chest 2007;132:368S-403S.

31. Lordan JL, Gascoigne A, Corris PA. The pulmonary physician in critical care * Illustrative case 7: Assessment and management of massive haemoptysis. Thorax 2003;58:814-9.

32. Tüller C, Tuller D, Tamm M, et al. Hemodynamic effects of endobronchial application of ornipressin versus terlipressin. Respiration 2004;71:397-401.

33. Cahill BC, Ingbar DH. Massive hemoptysis. Assessment and management. Clin Chest Med 1994;15:147-67.

34. Hayakawa K, Tanaka F, Torizuka T, et al. Bronchial artery embolization for hemoptysis: immediate and long-term results. Cardiovasc Intervent Radiol 1992;15:154-158, 158-159.

35. Fernando HC, Stein M, Benfield JR, et al. Role of bronchial artery embolization in the management of hemoptysis. Arch Surg 1998;133:862-6.

36. Marcelin C, Soussan J, Desmots F, et al. Outcomes of Pulmonary Artery Embolization and Stent Graft Placement for the Treatment of Hemoptysis Caused by Lung Tumors. J Vasc Interv Radiol 2018;29:975-80.

37. Wang GR, Ensor JE, Gupta S, et al. Bronchial artery embolization for the management of hemoptysis in oncology patients: utility and prognostic factors. J Vasc Interv Radiol 2009;20:722-9.

38. Osaki S, Nakanishi Y, Wataya H, et al. Prognosis of bronchial artery embolization in the management of hemoptysis. Respiration 2000;67:412-6.

39. Mal H, Rullon I, Mellot F, et al. Immediate and long-term results of bronchial artery embolization for life-threatening hemoptysis. Chest 1999;115:996-1001.
40. Syha R, Benz T, Hetzel J, et al. Bronchial Artery Embolization in Hemoptysis: 10-Year Survival and Recurrence-Free Survival in Benign and Malignant Etiologies - A Retrospective Study. Rofo 2016;188:1061-6.

41. Garzon AA, Gourin A. Surgical management of massive hemoptysis. A ten-year experience. Ann Surg 1978;187:267-71.

42. Dutau H, Palot A, Haas A, et al. Endobronchial embolization with a silicone spigot as a temporary treatment for massive hemoptysis: a new bronchoscopic approach of the disease. Respiration 2006;73:830-2.

43. Coiffard B, Laroumagne S, Plojoux J, et al. Endobronchial occlusion for massive hemoptysis with a guidewireassisted custom-made silicone spigot: a new technique. J Bronchology Interv Pulmonol 2014;21:366-8.

44. Bylicki O, Vandemoortele T, Laroumagne S, et al. Temporary endobronchial embolization with silicone spigots for moderate hemoptysis: a retrospective study. Respiration 2012;84: 225-30.

45. Lee SA, Kim DH, Jeon GS. Covered bronchial stent insertion to manage airway obstruction with hemoptysis caused by lung cancer. Korean J Radiol 2012;13:515-20.

46. Brandes JC, Schmidt E, Yung R. Occlusive endobronchial stent placement as a novel management approach to massive hemoptysis from lung cancer. J Thorac Oncol 2008;3:1071-2.

47. Chung IH, Park MH, Kim DH, et al. Endobronchial stent insertion to manage hemoptysis caused by lung cancer. J Korean Med Sci 2010;25:1253-5.

48. Lee P, Kupeli E, Mehta AC. Airway stents. Clin Chest Med 2010;31:141-50.

49. Song HY, Shim TS, Kang SG, et al. Tracheobronchial strictures: treatment with a polyurethane-covered retrievable expandable nitinol stent--initial experience. Radiology 1999;213:905-12.

50. Kim JH, Shin JH, Song HY, et al. Benign tracheobronchial strictures: long-term results and factors affecting airway patency after temporary stent placement. AJR Am J Roentgenol 2007;188:1033-8.

51. Nam DH, Shin JH, Song HY, et al. Malignant esophagealtracheobronchial strictures: parallel placement of covered retrievable expandable nitinol stents. Acta Radiol 2006;47:3-9.

Cite this article as: Zeng J, Wu X, Zhang M, Lin L, Ke M. Modified silicone stent for difficult-to-treat massive hemoptysis: a pilot study of 14 cases. J Thorac Dis 2020;12(3):956-965. doi: $10.21037 /$ jtd.2019.12.47 